\title{
PREDICTION ON MORPHOLOGICAL RESPONSE OF DREDGED SAND-BORROW PITS
}

\author{
Qimiao $\mathrm{Lu}^{1}$ and Robert B. Nairn ${ }^{1}$
}

Dredged pits in coastal zones are generally required for sand borrows for beach nourishment. The morphological response of borrow pits is important to evaluate future environmental impacts and potential impacts to adjacent seabed infrastructure such as pipelines. This paper will present the development of a simple concept model for the prediction of morphological response of dredged pits. A 3D hydrodynamic and sediment transport model was applied to verify the developed simple concept model. The case study for a sand-borrow pit on the offshore of Louisiana at the Atlantic coast of USA will be updated. The strengths and limitations of the developed model will be also discussed.

Keywords: sand-borrow pits, sedimentation; margin erosion; sediment transport modeling; morphological modeling; empirical formulae

\section{INTRODUCTION}

Dredged pits in coastal zones are generally required for sand borrows for beach nourishment. With the increased demand for beach nourishment, sand borrow pits are becoming increasingly deeper. The morphological response of borrow pits is important to evaluate future environmental impacts and potential impacts to adjacent seabed infrastructure such as pipelines.

There are at least two fundamental mechanisms contributing to morphological evolution in pits. The first is related to general sedimentation on the deposition of ambient sediment load in a locally more quiescent hydrodynamic condition created by the presence of the pit. The presence of the deepened water results in a reduction in the current velocity directly over the pit. The reduction in current speed over the pit results in a reduction to the capacity for sand transport and the deposition of some of the sediment including bed load and some fraction of the suspended load in the pit. The side slopes of the pit are flattened due to gravitational effects - as sediment is stirred by waves or currents, the effect of gravity is always contributing to down-slope movement.

The second is driven by morphological adjustment of the pit through margin erosion and related pit sedimentation. Modifications to flows beyond the edge of the pit caused by the dredging are generally small and limited to one to two times the length or width of the pit. The currents on the out-going edges of the pit are quickly recovered to the current level in the ambient area. Due to the sedimentation in the pit, the sediment load on the outgoing edge is reduced. The reduction results in the erosion on the outgoing edge of the pit. This second mechanism of sedimentation (i.e. margin erosion) becomes increasingly important to consider with deeper pits. It could potentially cause the instability of seabed infrastructure such as pipelines and significantly increase sedimentation in the pit.

Many studies on the morphological evolution of pits and navigation channels after dredge have been conducted through field surveys, theoretical analysis, physical modeling, and numerical modeling. The empirical equation for estimating sedimentation in a dredged channel was developed by Liu and Zhang (1983) in considering tide currents and waves. The equation was developed from detailed sedimentation studies over more than ten sites in coastal zones of China. These sites were mostly in mud or in a very fine sediment environment. The equation has been well verified in engineering practice and was successfully used to estimate the siltation volumes in a navigation channel oblique to the flow in a muddy environment. The siltation thickness was calculated per tide in transverse and longitudinal directions separately to distinguish the impacts of channel orientation on the flow. The key parameter in the equation was the background suspended sediment concentration which should be estimated from the field data or calculated from tide currents and wave heights in the absence of field measurement. The bed load was not considered in their empirical analysis. The equation may not be suitable for a dredged pit or channel in the coastal area where there are dominant sand or significant bed load. Additionally, the margin erosion which was mainly focused in this study was not included in their empirical analysis.

Seventeen institutes from seven countries of the European Community started a large study called SANDPIT. The purpose of the study was to better define near field and far field impacts of dredged pits for the purpose of improved Coastal Zone Management. The SANDPIT study focused mostly on

${ }^{1}$ Baird \& Associates, 1267 Cornwall Rd, Ste 100, Oakville, Ontario, L6J 5Z7, Canada 
sandy settings and primarily physical impacts of dredging. Physical impacts were assessed through large-scale laboratory and field experiments, analysis, and numerical modeling.

The SANDPIT study included two large-scale physical model tests at the University of Aberdeen and Delft Hydraulics, in addition to one full-scale field experiment specifically designed to develop a better understanding of sand transport processes over rippled beds in intermediate water depths without the presence of pits. A wide range of models were tested and many were refined through the course of the SANDPIT study. These efforts focused on predicting: bedforms, roughness, sand transport, and morphodynamics. The key models tested included: Delft3D (Delft); PISCES2DH/TELEMAC (HR Wallingford); TELEMAC with SISYPHE and two others (Sogreah); MIKE21 CAMS (DHI); and four other less-known models. In addition to these complex modeling approaches, a much simpler 1D analytical approach was developed using Bailard's transport equation and a representation of the spatial lag effects in suspended sediment concentration following the approach of Galappatti (see Ribberink et. al., 2005). Pit evolution was parameterized as a moving sand wave with the key unknown variables being migration speed and pit infilling (or damping). This practical and simple approach provided reasonable approximations of pit migration velocity and infilling time when compared to the Havinga (1992) and Van Rijn (1986) laboratory data and the Scheveningen test trench (Svasek, 1964).

A harmonic solution of the linearized model provided insight into the behavior of the model and pit infilling and migration. The results showed that there were three types of responses depending on the ratio of the length, $\mathrm{L}$ (or width) to the depth, $\mathrm{h}$ of the pit: 1$)$ the pit is so narrow $(\mathrm{L} / \mathrm{h}<10)$ that the suspended sediment does not respond to the pit and there is no pit migration contribution of suspended load (and thus migration rates are low); 2) a transition range (from $\mathrm{L} / \mathrm{h}$ of 10 to 100 or 1000 depending on the ratio of shear velocity to fall velocity) where longer/larger pits migrate faster due to an increasing contribution of suspended sediment to morphology change; and 3) an upper limit to migration speed (L/h greater than 100 or 1000 depending on the shear to fall velocity ratio) where essentially the two slopes act independently. Pit migration is dependent on a net or residual transport rate, usually either due to asymmetry in the wave or tidal transport components. At sites where surface waves contribute to stirring of the seabed sediment and increased bed and suspended load, the pit migration velocity is increased and therefore is proportional to the wave energy at a given site. For short or narrow pits infilling is the dominant process, whereas long or wide pits (i.e. in the direction of transport) are influenced equally by filling and migration. Longer trenches migrate faster and deep trenches migrate slower.

The SANDPIT researchers believe that pit migration and evolution is a key factor to understand as it effectively expands the area of influence and associated impacts with time (whether they relate to indirect physical impacts such as shoreline change or direct ecological effects such as the change of depths and substrate conditions). Clearly, pit migration is an important process to understand with respect to the stability of nearby fixed infrastructure.

A series of studies on the morphological evolution of the sand-borrow pits on the offshore of Louisiana and Florida have been completed by Nairn, et al., (2005, 2006), funded by the Minerals Management Service (MMS). The studies included a series of field surveys to monitor the morphological evolution, theoretical analysis, 2D/3D hydrodynamic and sediment transport modeling. The researchers found that pit evolution in sandy settings is influenced strongly by both bed load and suspended load. As a result of the importance of bed load the pit slope evolution and pit infilling are strongly coupled due to limited relaxation or adaptation effect. In contrast, the morphology of pits in muddy settings is more decoupled with pit infilling and pit margin occurring without strong morphologic interaction. Whereas pits in sandy settings can migrate where there is a net or residual transport rate, pits in muddy settings do not migrate, but pit margin erosion can be greater on one side than another.

This paper will present the development of the simple concept model for the prediction of morphological response of dredged pits. The case study on the sand-borrow pits on the offshore of Louisiana at the Atlantic coast of USA will be updated in the paper.

\section{METHODS}

The methods developed and used for the prediction of morphological changes for dredged pits include a simple concept model using the empirical function and a more comprehensive threedimensional hydrodynamic and sediment transport model. This section will describe these two models used for the prediction of morphological response for pits. 


\section{Simple Concept Model with Empirical Analysis}

\section{Sedimentation in Pits}

There are a few empirical equations for estimating the sedimentation in dredged channels. None of these equations have been used for margin erosion in pits. The empirical equation developed by Liu and Zhang (1983) is suitable for mud infilling in a dredged channel. The equation was developed from detailed sedimentation studies over more than ten sites in China and has been well verified in engineering practice. The equation can be used to estimate the siltation thickness per tide in a navigation channel oblique to the flow in a muddy environment. The siltation thickness is calculated in transverse and longitudinal directions separately to distinguish the impacts of channel orientation on the flow. The equation is written as:

$$
\Delta Z_{b}=\frac{C_{0} \omega_{s} T}{\rho_{d r y}}\left\{k_{1}\left[1-\left(\frac{h_{0}}{h_{p}}\right)^{3}\right] \sin \left(\alpha_{0}\right)+k_{2}\left[1-\frac{1}{2} \frac{h_{0}}{h_{p}}\left(1+\frac{h_{0}}{h_{p}}\right)\right] \cos \left(\alpha_{0}\right)\right\}(1)
$$

where $\Delta Z_{b}$ is total siltation thickness per tide (m/tide); $C_{0}$ is background concentration outside the dredged channel, which is generally determined by using the tide-mean and depth-averaged sediment concentration on the surrounding area $\left(\mathrm{kg} / \mathrm{m}^{3}\right) ; k_{1}$ and $k_{2}$ are empirical coefficients $\left(k_{l}=0.35\right.$ and $\left.k_{2}=0.13\right) ; \omega_{s}$ is settling velocity of mud, which may include the acceleration effects of cohesive sediment flocculation $(\mathrm{m} / \mathrm{s}) ; T$ is tidal period $(\mathrm{s}) ; h_{0}$ is water depth above the natural bed outside the channel $(\mathrm{m}) ; h_{p}$ is water depth inside the excavated channel $(\mathrm{m}) ; \rho_{d r y}$ is dry bulk density $\left(\mathrm{kg} / \mathrm{m}^{3}\right) ; \alpha_{0}$ is the angle between mean flow direction and channel orientation. $\alpha_{0}=90^{\circ}$ if the flow direction is perpendicular to the channel and $\alpha_{0}=0^{\circ}$ if the flow direction is parallel to the channel orientation.

Though the above equation was originally developed for channels, it can also be applied to assessing the infilling rate in a dredged pit. The flow over a dredged channel will increase if the channel is parallel to the flow as the deepening of the channel reduces the bottom friction. However, if the channel is perpendicular to the flow, the flow over the dredged channel will decrease in response to the greater water depth. The latter condition is the case for most dredged pits. The flow could be considered to be always perpendicular to the pit in all directions regardless of flow direction. Therefore, the equation for pit infilling rate can be rewritten as:

$$
\Delta Z_{p}=k_{1} \frac{C_{0} \omega_{s} T}{\rho_{d r y}}\left[1-\left(\frac{h_{0}}{h_{p}}\right)^{3}\right]
$$

The term $\left[1-\left(\frac{h_{0}}{h_{p}}\right)^{3}\right]$ in the equation accounts for the reduction of sediment load capacity due to flow reduction as water depth increases over the pit. $\Delta Z_{p}$ is the sedimentation thickness in one tide cycle (m/tide).

The important parameter in the above equations is the background suspended sediment concentration $\left(C_{0}\right)$, which should represent the long-term averaged suspended sediment concentration in the surrounding area. The most direct way to determine the background concentration is through long-term measurements at the site. If the seabed is in an equilibrium state (i.e. with no ongoing deposition), $C_{0}$ can be determined by using an empirical equation with average current and wave height (Liu and Zhang, 1983, van Rijn, 1986). If the seabed is in a depositional environment, the background concentration $\left(C_{0}\right)$ will consist of two parts: a) the concentration generated by currents and waves (equilibrium concentration); and b) the concentration delivered by external sources through advection/dispersion processes - the primary example being plumes from river discharge.

The equation to calculate background concentration was suggested by Liu (1983) is written as:

$$
C_{0}=0.0273 * \rho_{s} \frac{\left(U_{c}+U_{w}\right)^{2}}{g h}
$$


where $\rho_{s}$ is sediment density $\left(=2650 \mathrm{~kg} / \mathrm{m}^{3}\right), U_{c}$ is the average current speed, $U_{w}$ is the orbital velocity calculated using the average wave height; $h$ is water depth, and $g$ is gravitational acceleration $(=9.8$ $\left.\mathrm{m} / \mathrm{s}^{2}\right)$.

Settling velocity is required for the calculation. The flocculation of cohesive sediment is the main factor determining settling velocity, and this process depends on salinity and concentration. The settling velocity increases as salinity increases up to $15 \mathrm{ppt}$ and as concentration increases up to 1,000 $\mathrm{mg} / \mathrm{l}$. On the basis of physical measurements and lab tests (see van Rijn, 1998), the mean settling velocity is in the range of $0.0005 \mathrm{~m} / \mathrm{s}$ to $0.003 \mathrm{~m} / \mathrm{s}$, depending on cohesiveness of sediment, salinity, and concentration.

The dry density of deposited mud is very dependent on the degree of consolidation that increases with time after deposition. There are three stages of consolidation: initial (days), intermediate (weeks), and final (years). Dry density of highly consolidated sediment (about 1 year old) ranges from 400 to $550 \mathrm{~kg} / \mathrm{m}^{3}$ (corresponding to wet density in the range of 1,250 to $1,350 \mathrm{~kg} / \mathrm{m}^{3}$ ).

\section{Margin erosion in Pit}

Margin erosion was observed in the pit margin of the Holly Beach Dredge Pit. As flow leaves the pit and water depth is reduced, the flow speed increases to match the ambient flow speed in the absence of the pit. The sediment load capacity of the flow at the outgoing edge is similar to the load capacity at the incoming edge. However, the suspended sediment concentration at the outgoing edge is less than capacity due to deposition in the pit once the flow accelerates to ambient flow speed. This results in bed erosion beyond the outgoing edge to restore sediment concentration to an equilibrium level. An equation to estimate pit margin erosion was developed on the basis of one-dimensional sediment transport equation under steady condition, which is written as

$$
\rho_{d r y} \frac{\partial Z_{b}}{\partial t}=-\frac{\partial q_{s}}{\partial x}=\beta \omega_{s}\left(c_{b}-c_{b, e}\right)
$$

where $Z_{b}$ is the bed elevation $(\mathrm{m}) ; c_{b}$ is sediment concentration near the bed $\left(\mathrm{kg} / \mathrm{m}^{3}\right)$. It can be expressed as $c_{b}=\eta C$, in which $C$ is depth-averaged sediment concentration and $\eta$ is an adjustment parameter for non-uniform vertical distribution of sediment concentration; $\beta$ is the probability of sediment settling between 0 to $1 ; c_{b, e}$ is equilibrium near bed sediment concentration $\left(\mathrm{kg} / \mathrm{m}^{3}\right) ; x$ is distance in the flow direction; $q_{s}$ is total suspended sediment load, which is expressed by

$$
q_{s}=\int_{0}^{h} u c d z=\alpha U h C
$$

in which, $u$ is flow velocity $(\mathrm{m} / \mathrm{s})$; and $c$ is concentration $\left(\mathrm{kg} / \mathrm{m}^{3}\right), U$ is depth averaged flow velocity $(\mathrm{m} / \mathrm{s}), h$ is water depth $(\mathrm{m})$, and $\alpha$ is the adjustment parameter for non-uniform vertical distribution of sediment load. Using depth-averaged values for all variables in the above equations, the equations can be rewritten as

$$
\begin{gathered}
\rho_{d r y} \frac{\partial Z_{b}}{\partial t}=-\alpha \frac{\partial(U h C)}{\partial x} \\
\alpha \frac{\partial(U h C)}{\partial x}=-\beta \eta \omega_{s}\left(C-C_{e}\right)
\end{gathered}
$$

In order to determine the pit margin erosion, suspended sediment concentration at the outgoing edge is first determined by applying Equation (5) to determine the reduction in sediment concentration due to the deposition across the pit, i.e. between the cross-section $X_{0}$ to $X_{1}$ (see Figure 1). Assume that the unit width flow flux at the incoming edge is the same as the outgoing edge, i.e. $U_{1} h_{1}=U_{0} h_{0}$. Therefore, the concentration on the outgoing edge at the cross-section $X_{l}$ is determined by

$$
C_{1}=C_{0}\left\{1-\lambda_{1} \frac{\omega_{s}}{U_{0}} \frac{L_{p}}{h_{0}}\left[1-\left(\frac{h_{0}}{h_{p}}\right)^{3}\right]\right\}
$$


in which, $C_{l}$ are the depth averaged concentration at the incoming edge and the outgoing edge, respectively $\left(\mathrm{kg} / \mathrm{m}^{3}\right)$; and $L_{p}$ is the length of the pit at the flow direction $(\mathrm{m}) ; \lambda_{1}$ is a combined constant $\left(=k_{1} / \alpha\right)$. By applying Equation (6) to the reach on the pit margin, for example between Cross-section 1 and Cross-section 2 as shown in Figure 1 and replacing $C_{l}$ with Equation (7), the margin erosion at the outgoing edge of the pit is estimated as

$$
\Delta Z_{e}=\lambda_{2} \frac{\omega_{s} C_{0} T}{\rho_{d r y}}\left\{1-\left(\frac{h_{0}}{h_{1}}\right)^{3}-\lambda_{1} \frac{\omega_{s}}{U_{0}} \frac{L_{p}}{h_{0}}\left[1-\left(\frac{h_{0}}{h_{p}}\right)^{3}\right]\right\}
$$

where $\Delta Z_{e}$ is the erosion depth in one tide cycle at the edge of the pits (m/tide); $\lambda_{2}=\beta \eta$ is the combined constants relevant to the uniformity of vertical concentration distribution and the probability of sediment settling or the reduction of erosion rate due to bed sediment consolidation on the pit margin.

The combined constants, $\lambda_{1}$ and $\lambda_{2}$, should be calibrated with the measured data. The combined constant, $\lambda_{1}$, depends on the constant $k_{l}$ and the constant $\alpha$. The constant $\alpha$ represents the ratio of total suspended sediment load calculated by using non-uniform distribution of sediment concentration and flow velocity through the water column calculated by using depth-averaged concentration and flow velocity. A value of 1 represents sediment load under a uniform concentration distribution and flow velocity through the water column. Therefore, the value of $\alpha$ should be larger than 1 because a higher sediment load near the bed enhances sediment exchange and erosion/deposition processes. Therefore, the constant $\lambda_{1}$ should be less than 0.35 . Since the concentration profile depends on settling velocity and the vertical diffusivity coefficient, the constant is a function of sediment grain size and the strength of turbulence. The constant should be less for coarser sediment. The constant $\lambda_{2}$ depends on the probability of settling, an adjustment parameter for non-uniform distribution of sediment load (i.e. constant $\alpha$ ), an adjustment parameter for non-uniform distribution of sediment concentration, the flow condition, and the bed material. Since there are no direct data to determine the constant and it has a complicated physical meaning, it can only be determined through calibration. For a uniform vertical distribution of concentration and no sediment consolidation to the edge, such as mud environment, $\lambda_{1}=$ 0.35 and $\lambda_{2}=1$ are recommended.

Equations (2) and (8) should be solved together using the iteration approach, since $h_{l}$ and $h_{p}$ is the function of time, i.e. $h_{1}=h_{0}-\sum \Delta Z_{e}$ and $h_{p}=h_{0}-\sum \Delta Z_{p}$. Figure 2 shows the sedimentation rate and margin erosion rate per tide calculated using the parameters for Holly Beach Pit. As the water depth in the pit decreases due to deposition, the sedimentation rate in the pit decreases. The seabed at the pit edge is initially eroded and then turns to the slight deposition situation.

$$
\mathrm{X}_{1} \quad \mathrm{X}_{2}
$$

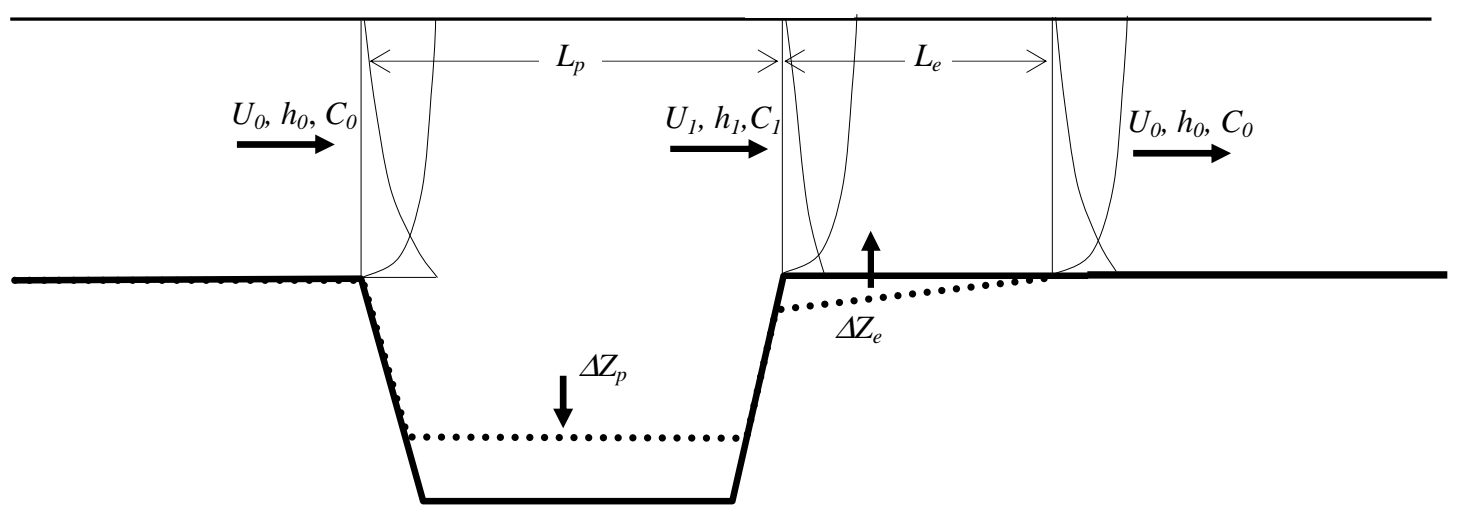

Figure 1 Pit Infilling and Pit Margin Erosion Processes Conceptual Diagram. 


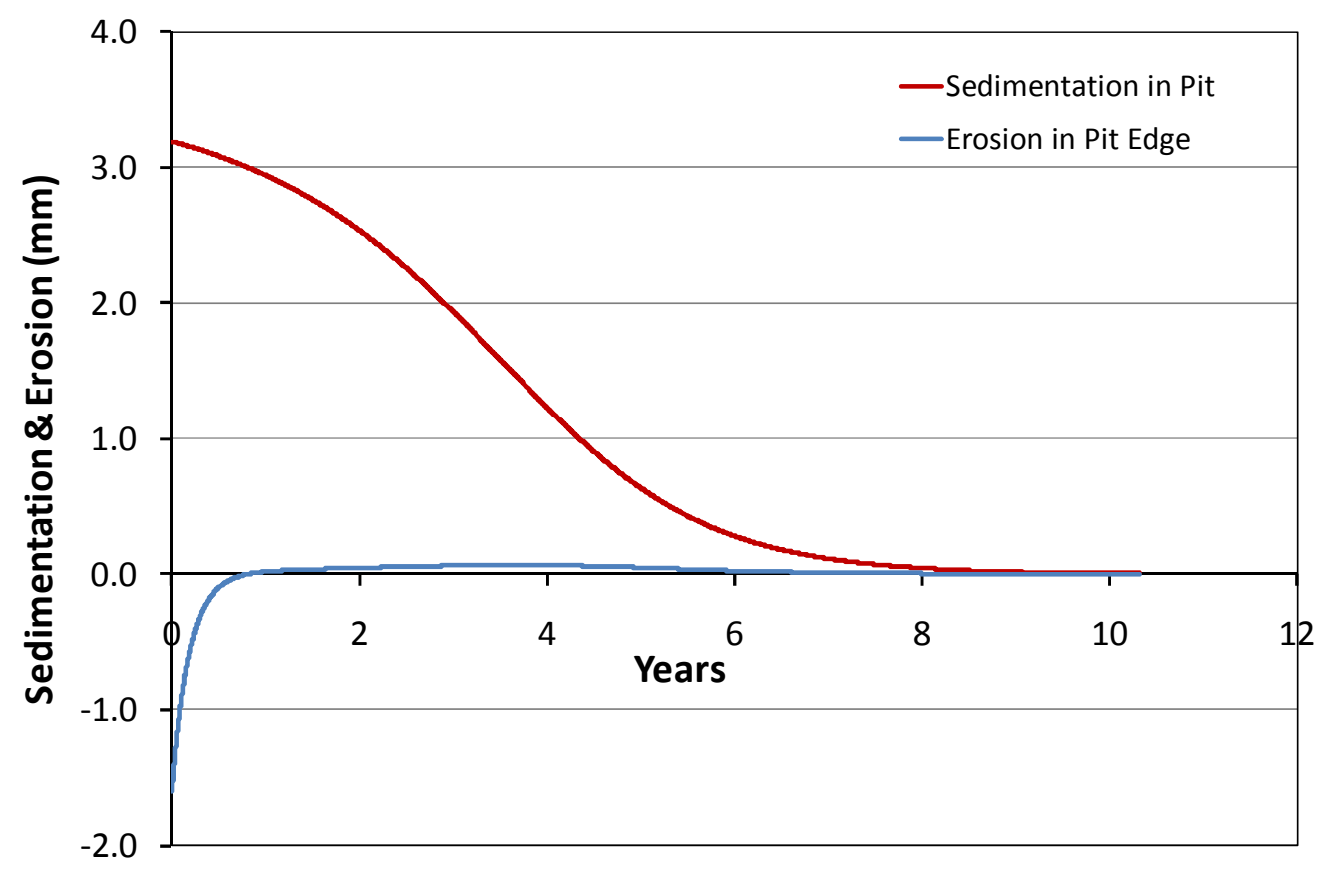

Figure 2 Sedimentation in a dredged pit and erosion at a pit edge

\section{Mathematical Modeling}

A 3D numerical model was also applied to simulate hydrodynamics, sediment transport, and morphologic changes in and around the pits. The objective of the numerical modeling analysis was to verify the simple analytical approach described above and to develop an improved understanding of the process. A three-dimensional hydrodynamic and sediment transport model, called MISED, was used for this study.

MISED is a three-dimensional finite element model that simulates tidal flow, temperature, salinity, sediment transport, and morphology in rivers, estuaries, and coastal and open sea areas. The model utilizes a new numerical method that is highly efficient and unconditionally stable. This numerical method allows for much larger time steps than other models such as MIKE3, ADCIRC, POM, and RMA2. The model is equipped with a robust drying up technique to deal with drying and wetting processes on flat floodplains and wetland. It can be applied to simulate tidal circulation in large areas, wind driven currents, stratified flow, sediment transport, erosion and deposition of sandy and cohesive sediments, advection-dispersion of thermal plumes, pollutants and contaminants, and to assess the impacts of a variety of coastal engineering structures including floating and submerged structures on surrounding environments. Details of the model are presented in Lu and Wai (1998).

\section{CASE STUDY - HOLLY BEACH SAND-BORROW PIT}

Holly Beach sand-borrow pit is located at an $8 \mathrm{~m}$ water depth on the offshore of Louisiana State, Gulf of Mexico. Along the Louisiana and Texas portions of the Gulf of Mexico, there are many instances of buried paleo-channels that were formed in river valleys at lower sea level stands. These deposits represent a significant source of sand for coastal restoration. However, the seafloor of the 
outer continental shelf offshore Louisiana is predominantly muddy. Once the muddy cover is stripped, suitable sand deposits of sand are exposed. The Holly Beach Restoration project was completed in 2003. A series of studies on the pit morphological evolution including field surveys, numerical modeling, and post-project monitoring were completed after the pit was constructed (Nairn et. al., 2005, 2006). The details of physical conditions, modeling approaches, and the predictions were described in the paper (Nairn et. al., 2006). This paper updates the comparison of predicted sedimentation with the additional field surveyed data.

In order to monitor the morphological evolution of the pit, two additional field surveys were conducted in June, 2006 and March, 2007, after the modeling prediction study was completed. The measured water depth under the chart datum was compared with the water depth predicted by using both a simple concept model and the 3D numerical model. The two red points shown in the figure represent the water depth measured in the pit after the study was completed. These agree well with the prediction of both models.

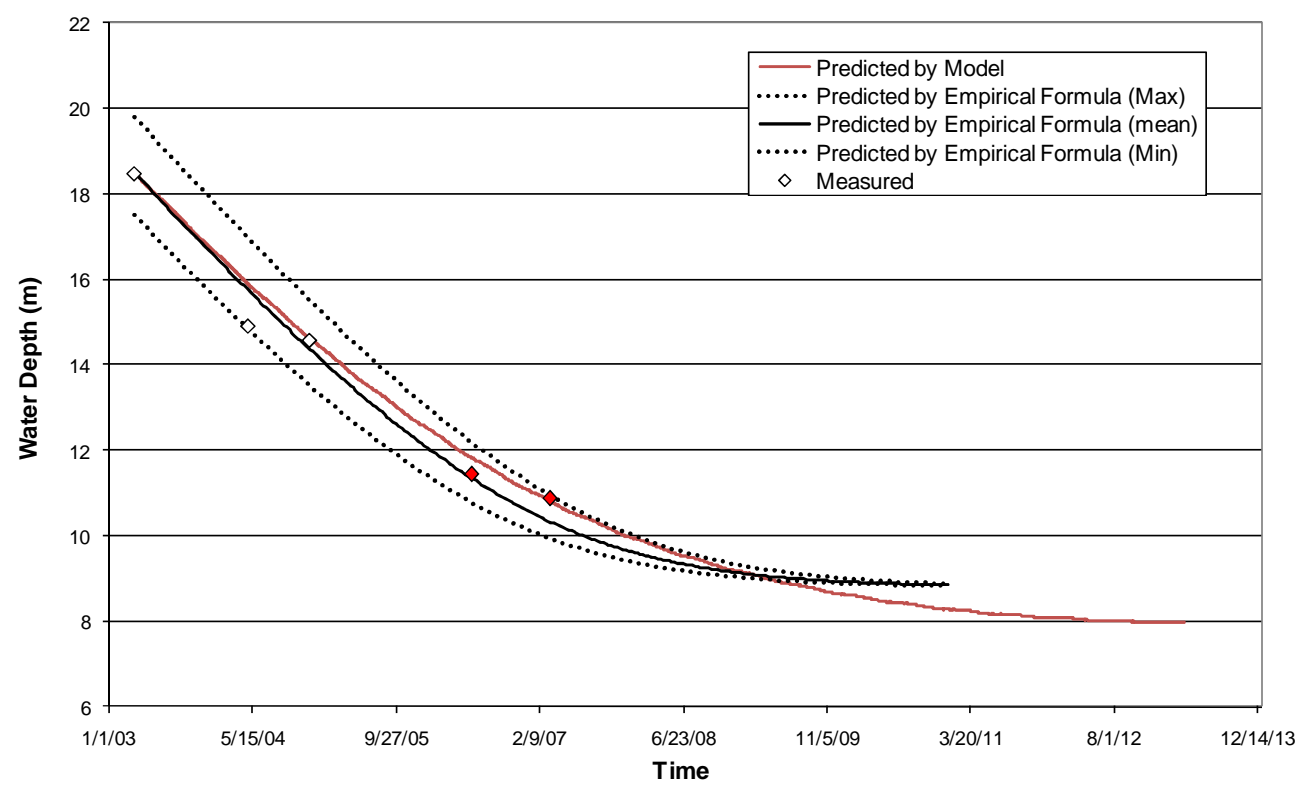

Figure 3 Comparison of predicted sedimentation by the models with the field measured data. The red points were measured after the study was completed.

The comparison of bed elevation predicted by the 3D model and measured from the field along the pit profile is shown in Figure 4. The two sets of measured bathymetry in June, 2006 and March, 2007 after the study was completed were also added in the figure. The measured bed elevations shown in the figures were extracted along the profiles in a North-South direction and a Southwest-Northeast direction from the measured bathymetry. The bed elevation predicted by the model in both the inside of pit and the margin agree well with the measured bed elevations. Both model results and measured data show that the pit margin erosion occurred at the first one and half years after the dredge. The margin erosion decreases as the pit is filled up. This feature of morphological change was found to be similar as described by the empirical formula (see Figure 2). 


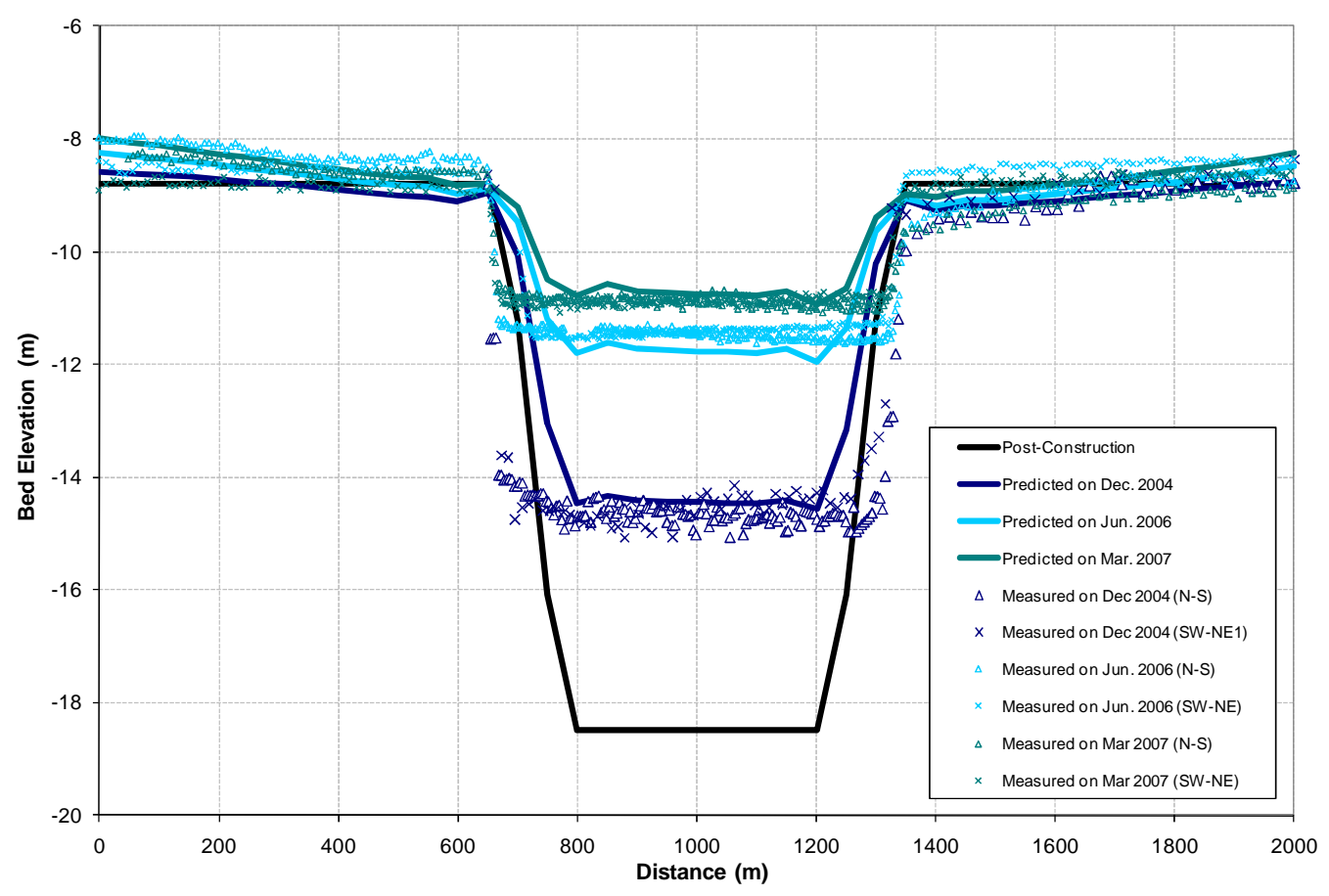

Figure 4 The comparison of bed elevation change predicted by the 3D model with the measured data.

\section{CONCLUSIONS}

The simple concept model to predict the morphological evolution for a sand-borrow pit was developed through this study. The developed model was well calibrated and validated against the survey data in the Holly Beach Sand-Borrow Pit. It provides a simple and efficient tool for estimating sedimentation rate in a pit and the margin erosion on the edge of the pit. However, based on the assumption, the developed model may only be applied to a pit in muddy settings. The impact of the dredge on the current is not considered in the model. Therefore, the developed model is suitable for assessing sedimentation rate and margin erosion in a pit with simple configuration or for screen-level assessment. For the complex hydrodynamic environment, a more comprehensive model, i.e. a threedimensional sediment transport model should be used for accurately estimating sedimentation rate and margin erosion in a pit.

Through this study, unlike pits with sandy settings which can migrate where there is a net or residual transport rate, pits in muddy settings do not migrate. The significant margin erosion for the pits occurs only at the beginning after the dredge is completed. The margin erosion decreases as the pit is filled up until there is no erosion or slight accretion after one and half years, as found in both field data and modeling analysis.

\section{REFERENCES}

Havinga, F.J., 1992. Sediment concentrations and sediment transport in case of irregular non-breaking waves with current. Report H480. Delft Hydraulics, Delft, The Netherlands.

Liu, J.J. and J.C. Zhang, 1983. Siltation study of some extension projects of the Lianyun Harbor, Int. Conf. On Coastal and Port Engineering in Developing Countries, Colombo, Sri Lanka, p11391147

Lu, Q. and Wai, O.W.H., 1998. An Efficient Operator Splitting Scheme for Three-dimensional Hydrodynamic Computations, International Journal of Numerical Methods in Fluid, 26, 771-789. 
Nairn, R.B., Q. Lu and B.S. Drucker, 2006. Evolution of Dredged Pits Offshore Louisiana And Buffers Around Seabed Infrastructure, Int. Conf. Of Coastal Engineering, Paper 404

Nairn, R.B., Q. Lu, and Langendyk, S.K., 2005. A study to address the issue of seafloor stability and the Impact on Oil and Gas infrastructure in the Gulf of Mexico. U.S. Dept. of the Interior, MMS, Gulf of Mexico OCS Region, New Orleans, L.A. OCS Study MMS 2005-043. 179 pp. + appendices.

Ribberink, J.S., Roos, P.C. and Hulscher, J.H.M., 2005. Morphodynamics of Trenches and Pits Under the Influence of Currents and Waves - Simple Engineering Formulas. Proc. of Coastal Dynamics '05. ASCE.

Svasek, J.N., 1964. Behaviour of trial dredge trench in the sea bed of the North Sea near Scheveningen (in Dutch). Report Deltadienst, the Hague, The Netherlands.

Van Rijn, L.C., 1986. Sedimentation of Dredged Channels by Currents and Waves. J. Waterway, Port, Coastal and Ocean Engineering, Vol. 112, No. 5, p. 541-559.

Van Rijn, L.C., Soulsby, R.L., Hoekstra, P. and Davies, A.G., (editors). 2005. SANDPIT, Sand Transport and Morphology of Offshore Sand Mining Pits. Process knowledge and guidelines for coastal management. End Document, May 2005. Part 1. EC Framework V Project No. EVK32001-00056. Aqua Publications, The Netherlands. 